\title{
Erratum to: Characterization of Bioethanol Production from Hexoses and Xylose by the White Rot Fungus Trametes versicolor
}

Rasika L. Kudahettige • Marie Holmgren •

Peter Immerzeel • Anita Sellstedt

Published online: 6 April 2011

(C) Springer Science+Business Media, LLC. 2011

Erratum to: Bioenerg. Res.

DOI 10.1007/s12155-011-9119-5

The original version of this article unfortunately contained an error in one of the co-author's names. Peter Imerzeel should be spelled as Peter Immerzeel.

The online version of the original article can be found at http://dx.doi. org/10.1007/s12155-011-9119-5.

R. L. Kudahettige $(\square) \cdot$ M. Holmgren $\cdot$ A. Sellstedt

Department of Plant Physiology, Umeå Plant Science Centre,

Umeå University,

90187 Umeå, Sweden

e-mail: rasika.kudahettige@plantphys.umu.se

P. Immerzeel

Department of Biochemistry, University of Lund,

Getingevägen 60,

22241 Lund, Sweden 